\title{
What is the difference in concussion management in children as compared with adults? A systematic review
}

\author{
Gavin A Davis, ${ }^{1}$ Vicki Anderson, ${ }_{1}^{1}$ Franz E Babl, ${ }_{1}^{1}$ Gerard A Gioia, ${ }^{2}$ Christopher C Giza, ${ }^{3}$ \\ William Meehan, ${ }^{4}$ Rosemarie Scolaro Moser, ${ }^{5}$ Laura Purcell, ${ }^{6}$ Philip Schatz, ${ }_{1}^{7}$ \\ Kathryn J Schneider, ${ }^{8}$ Michael Takagi, ${ }^{1}$ Keith Owen Yeates, ${ }^{9}$ Roger Zemek ${ }^{10}$
}

\begin{abstract}
${ }^{1}$ Murdoch Childrens Research Institute, Melbourne, Australia ${ }^{2}$ Children's National Health System, Maryland, USA ${ }^{3}$ UCLA Steve Tisch BrainSPORT Program, Los Angeles, USA ${ }^{4}$ Micheli Center for Sports Injury Prevention, Massachusetts, USA ${ }^{5}$ Sports Concussion Center of New Jersey, New Jersey, USA ${ }^{6}$ Department of Pediatrics, McMaster University, Hamilton, Ontario, Canada

${ }^{7}$ Saint Joseph's University, Pennsylvania, USA

${ }^{8}$ Sport Injury Prevention Research Centre, Faculty of Kinesiology, Alberta Children's Hospital Research Institute, Hotchkiss Brain Institute, Cummings School of Medicine, University of Calgary, Calgary, Canada

${ }^{9}$ Department of Psychology, Alberta Children's Research Institute \& Hotchkiss Brain Institute, University of Calgary, Calgary, Canada ${ }^{10}$ Department of Pediatrics, Children's Hospital of Eastern Ontario, University of Ottawa, Ottawa, Canada
\end{abstract}

\section{Correspondence to}

Prof Gavin A Davis, Suite 53 Neurosurgery, Cabrini Medical Centre Malvern, Victoria 3144 Australia; gavin.davis@me.com

Accepted 22 February 2017 Published Online First 28 February 2017

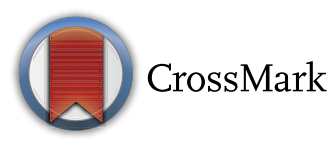

To cite: Davis GA, Anderson V, Babl FE, et al. Br J Sports Med

2017;51:949-957.

\section{ABSTRACT}

Aim To evaluate the evidence regarding the management of sport-related concussion (SRC) in children and adolescents. The eight subquestions included the effects of age on symptoms and outcome, normal and prolonged duration, the role of computerised neuropsychological tests (CNTs), the role of rest, and strategies for return to school and return to sport (RTSp). Design Systematic review.

Data sources MEDLINE (OVID), Embase (OVID) and Psyclnfo (OVID).

Eligibility criteria for selecting studies Studies were included if they were original research on SRC in children aged 5 years to 18 years, and excluded if they were review articles, or did not focus on childhood SRC. Results A total of 5853 articles were identified, and 134 articles met the inclusion criteria. Some articles were common to multiple subquestions. Very few studies examined SRC in young children, aged 5-12 years.

Summary/conclusions This systematic review recommends that in children: child and adolescent agespecific paradigms should be applied; child-validated symptom rating scales should be used; the widespread routine use of baseline CNT is not recommended; the expected duration of symptoms associated with SRC is less than 4 weeks; prolonged recovery be defined as symptomatic for greater than 4 weeks; a brief period of cognitive and physical rest should be followed with gradual symptom-limited physical and cognitive activity; all schools be encouraged to have a concussion policy and should offer appropriate academic accommodations and support to students recovering from SRC; and children and adolescents should not RTSp until they have successfully returned to school, however early introduction of symptom-limited physical activity is appropriate.

Systematic review registration PROSPERO 2016:CRD42016039184

\section{INTRODUCTION}

Sport-related concussion (SRC) in children is very common, although the true incidence is not known. About 4 million children are estimated to present annually to emergency departments (EDs) worldwide with concussion, ${ }^{1-3}$ which is estimated to represent only $12 \%$ of children with concussion. ${ }^{4}$ This suggests that annually about 33 million children worldwide sustain a concussion.

The International Concussion in Sport Group (CISG) first published a summary and agreement statement on the management of SRC in 2001, but this paper did not include any child-specific recommendations. The CISG meeting in Prague in 2004 briefly referred to the paediatric population, ${ }^{6}$ and the Zurich 2008 meeting expanded the consensus statement to include a section devoted to 'the child and adolescent athlete'. This statement included an age limit of 10 years for application of the recommendations, recommended a conservative approach to rest and return to school and play, introduced the Sport Concussion Assessment Tool 2nd edition (SCAT2), and offered a standard assessment approach for adults and children aged 10 years and over. Following the Zurich 2012 meeting, the consensus statement was expanded to include the age limit of 13 years, below which child-specific recommendations applied, including the development of the child-specific ChildSCAT3 for children aged 5-12 years. ${ }^{8}$ The statement also addressed children's cognitive requirements, the need for school accommodations, the use of neuropsychological testing in children, and specific considerations for children with learning disabilities and attention deficit hyperactivity disorder (ADHD).

Despite the increased interest and contributions to the literature over recent years, many knowledge gaps remain concerning SRC in children. This review was conducted to inform the 5 th International Consensus Conference on Concussion in Sport in Berlin 2016 on the published evidence on children and adolescents with SRC.

The aim of this review was to address the following questions as they relate to child SRC:

1. In which age groups should children be managed differently from adults?

2. Which symptoms and signs are most accurate for the diagnosis of concussion in children?

3. Is computerised neuropsychological testing (CNT) accurate for diagnosing and assessing recovery of concussion in children?

4. What is the 'normal' duration for recovery of concussion in children?

5. What are the predictors of prolonged recovery of concussion in children?

6. How long should children with concussion rest?

7. What factors must be considered in 'return to school' following concussion and what strategy or accommodations should be followed?

8. When should children with concussion return to sport (RTSp)? 


\section{METHODS}

\section{Literature identification}

We developed a search strategy that was independently peer reviewed by a librarian with expertise in systematic reviews. The search strategy incorporated two parts:

- Part 1: a general search strategy with the key constructs children and SRC

- Part 2: a specific search strategy for each of the eight subquestions for this systematic review (outlined in the aims section).

The general search strategy (part 1) was run before being combined with the specific search strategy (part 2) relevant to each individual question. The search terms for parts 1 and 2 are available on the PROSPERO website (http://www.crd.york.ac. uk/PROSPEROFILES/39184_STRATEGY_20160720.pdf).

We searched the Ovid MEDLINE, Ovid Embase, PsycInfo electronic databases, in addition to reviewing reference lists of retrieved articles, existing literature and systematic reviews to identify any potentially eligible articles that may have been missed in the electronic database search.

\section{Article selection}

Studies were eligible for inclusion if they were original research on SRC in children aged between 5 years and less than 18 years, published in English between 1985 and May 2016. Because of the paucity of studies that are specific to SRC in younger children, we included some studies which were not sport-specific, but in which the mechanism of injury was similar to sporting injuries, such as playground falls. Further, relevant papers presented and discussed by the panel at the Berlin meeting were subsequently included.

Studies were excluded if they included moderate or severe traumatic brain injuries or if they included patients with no clear history of head trauma or patients who sustained non-accidental injury. Because the focus was on children and sport, studies were excluded if they included mixed age cohorts and did not report child data separately from adult data, or if they concerned preschool age children. We excluded review articles, editorials, case reports, opinion articles and letters to the editor. Studies examining tools such as the ChildSCAT3, visual assessment (eg, King Devick) and complex balance assessment were not included, because these were the subject of separate systematic reviews at the Berlin meeting.

\section{Data extraction}

Two independent reviewers screened the titles and abstracts of all records identified in each search. Full text articles were obtained and screened independently by the two reviewers for all abstracts potentially meeting inclusion criteria. If both reviewers agreed, the article was included for review. Discrepancies were resolved by consensus, and a third reviewer was consulted if consensus could not be reached. Some papers were the product of multiple searches; the data relevant to the specific question of each search were extracted separately.

\section{Risk of bias assessment}

The Newcastle-Ottawa Scale was used to assess the risk of bias. ${ }^{9}$ This assessment was performed by each subgroup of authors performing the review for each subquestion. Discrepancies were resolved by consensus, and a third reviewer was consulted if consensus could not be reached.

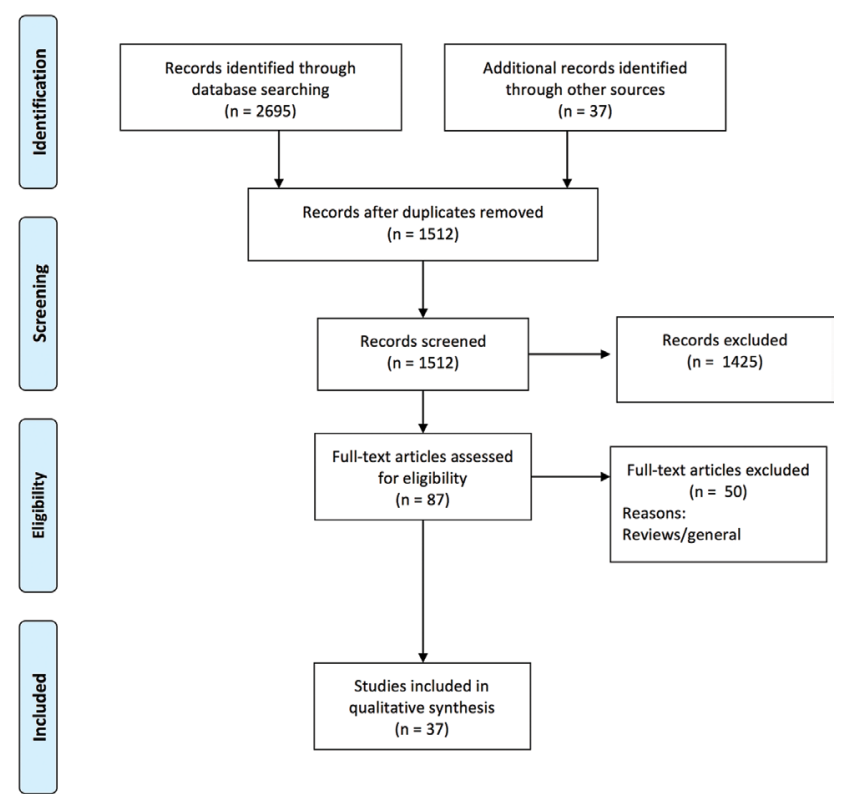

Figure 1 PRISMA flow diagram for search results for subquestion (1) In which age groups should children with SRC be managed differently from adults?

\section{Level of evidence}

The level of evidence of each study reviewed was assessed using The Oxford 2011 Levels of Evidence. ${ }^{10}$ This assessment was performed by each subgroup of authors performing the review for each subquestion. Discrepancies were resolved by consensus, and a third reviewer was consulted if consensus could not be reached.

\section{Data synthesis}

We completed a qualitative analysis of included articles, structured according to the eight subquestions outlined in the aims section. Data were synthesised descriptively and summary data presented in table form.

\section{RESULTS}

We identified 5853 potentially eligible articles, and finally 134 articles were included in this systematic review. The majority of articles addressed the adolescent population, rather than younger children (aged 5-12 years), and the overall level of evidence was level 2 for four articles, and levels 3 or 4 for all other articles (online supplementary tables $1-8$ ). There were only two randomised controlled trials (online supplementary tables 6,7).

\section{(1) In which age groups should children with SRC be managed differently from adults?}

Thirty-seven articles were included that addressed this question (figure 1); the results are summarised in online supplementary table $1 .^{11-47}$ In recognition that the age range of this review covers a time of extensive brain maturation and crosses over several functional developmental stages, we paid attention to how age was treated across studies. For the most part, the studies considered age in one of five ways: (1) developmentally (eg, using categories of $5-7$ years vs $8-9$ years vs $10-12$ years, etc); (2) educationally (eg, high school vs middle school); (3) based on sport level (eg, bantam vs midget in ice hockey); (4) using age as a continuous variable; or (5) using an age grouping due to sample convenience. When age was considered developmentally, there was often no clear rationale or theory described in the 


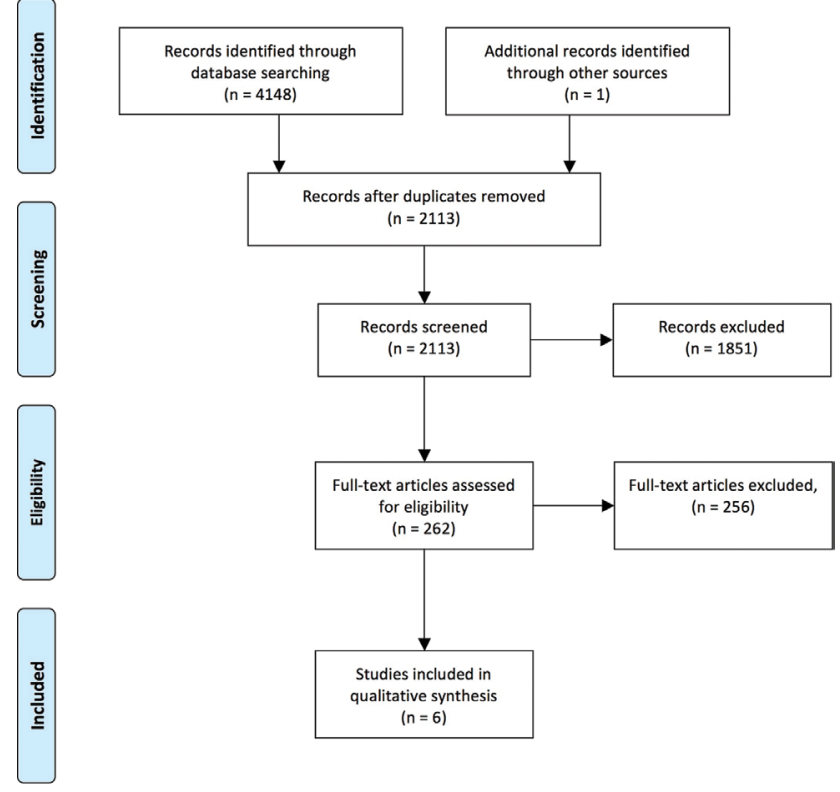

Figure 2 PRISMA flow diagram for search results for subquestion (2) Which symptoms and signs are associated with the diagnosis of concussion in children with SRC?

study for adopting the specific age cut-offs. In other studies, age was studied as a continuous variable or not evaluated explicitly.

By aggregating the start and end points in the reviewed studies applying developmental age groupings, we concluded that ages $5,8,10,12,13,15$ and 18 years were most often used to identify the start or end of an age group. The age of 12 years was clearly the midpoint, being used most frequently in the studies to divide younger from older children. The number of studies on children under the age of 12 years is quite limited.

The literature does not adequately address the question of age groups in which children with SRC should be managed differently from adults.

\section{(2) Which symptoms and signs are associated with the diagnosis of concussion in children with SRC?}

Six articles were included that addressed this question (figure 2); the results are summarised in online supplementary table $2 .^{39}$ 48-52 Although total scores on symptom scales can reliably distinguish between youth with and without SRC, essentially no studies have rigorously examined specific symptoms and signs for their diagnostic or prognostic value.

Some data suggest that headaches, fatigue and dizziness are especially common symptoms after SRC in youth, but their diagnostic sensitivity/specificity is uncertain. Those same acute symptoms have also been associated with poorer outcomes, but again the studies are limited and not of high rigour.

Signs such as loss of consciousness, retrograde and anterograde amnesia, balance problems, and disorientation also are likely to have diagnostic and prognostic value, but data specifically within SRC in youth are very limited. Some evidence suggests that youth who play sports resulting in repetitive head contacts may show indications of neurocognitive or neurophysiological changes in the absence of diagnosed concussion or overt signs or symptoms of concussion. There were no data available to determine whether or how the early signs and symptoms of concussion differ in younger children as compared with older children or adolescents.

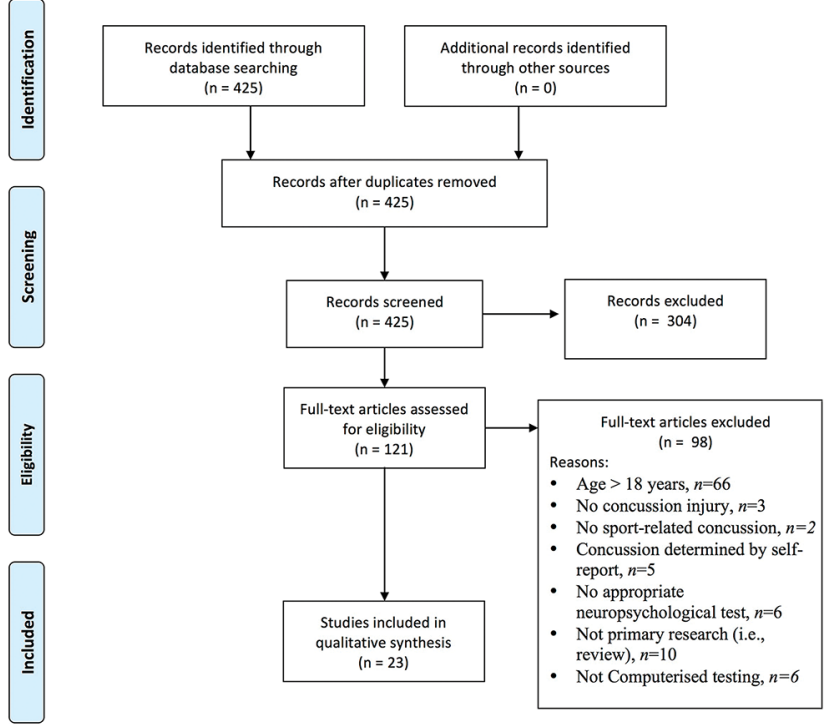

Figure 3 PRISMA flow diagram for search results for subquestion (3) Is computerised neuropsychological testing (CNT) accurate for diagnosing and assessing recovery of sport-related concussion in children?

\section{(3) Is CNT accurate for diagnosing and assessing recovery of SRC concussion in children?}

Twenty-three articles were included that addressed this question (figure 3); the results are summarised in online supplementary table $3 .^{205052-72}$ The majority of participants were male, while one study did not report sex. The majority of studies involved adolescents/high school students, rather than younger children.

Both computerised and standard paper-and-pencil neuropsychological tests were able to detect cognitive impairments acutely (within 48 hours of injury) and in the short/medium time period (10-14 days) postinjury. The most common neuropsychological deficits occurred in processing speed, verbal and visual memory, and reaction time.

A recent study incorporating the use of baseline CNT in youth ice hockey players demonstrated that concussed athletes were found to both improve and decline beyond reliable change metrics when compared with baseline, and the authors recommended caution in interpreting CNT results when using baseline testing. ${ }^{73}$ Similar findings of variability in baseline and postconcussion performance in athletes aged 11-17 years using CNT have been reported. ${ }^{74}$

\section{(4) What is the 'normal' duration for recovery of SRC in children?}

Twenty-four articles were included that addressed this question (figure 4); the results are summarised in online supplementary table 4. ${ }^{16}$ 19-22 315065 74-89 The method of measuring recovery varied based on clinical criteria used, and the cohorts were inconsistent, with some representing referred groups with persistent symptoms seeking expert management advice and others describing groups recruited acutely in ED settings. The vast majority of children recover from SRC and return to play or school within 4 weeks, but, similar to adolescent and collegiate athletes, a significant proportion of children experience concussion-related symptoms beyond 1 month after injury. Limited evidence suggests that adolescents may take longer to recover than young children and college students. 


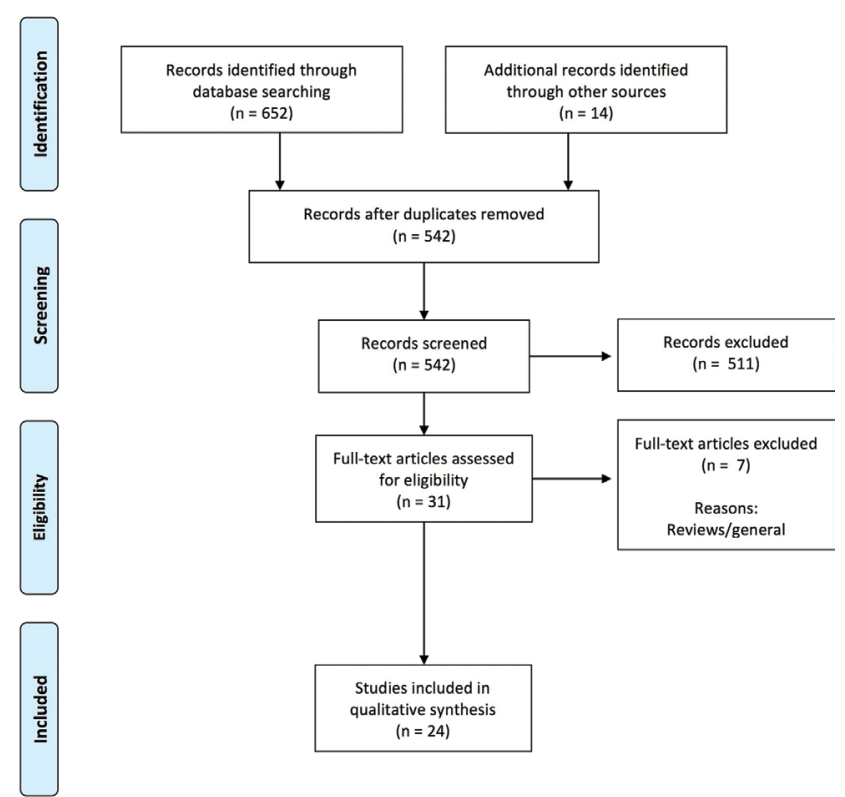

Figure 4 PRISMA flow diagram for search results for subquestion (4) What is the 'normal' duration for recovery of SRC in children?

\section{(5) What are the predictors of prolonged recovery of concussion in children?}

Eighteen articles were included that addressed this question (figure 5); the results are summarised in supplementary table 5. ${ }^{1316314445495890-100}$ The incidence of prolonged recovery varied significantly across studies, based on definitions and patient selection, with a range of approximately $11 \%$ to $55 \%$, (average approximately 30\%). The time point for assessment of prolonged symptoms was variable, and included 2 weeks, 1 month and 3 months, and the method for identifying persistent postconcussive symptoms (PPCS) was also variable.

The largest cohort study ${ }^{44}$ examined 3063 patients who were recruited within 48 hours of head injury in an ED setting and were not restricted to SRC. PPCS (which required persistence

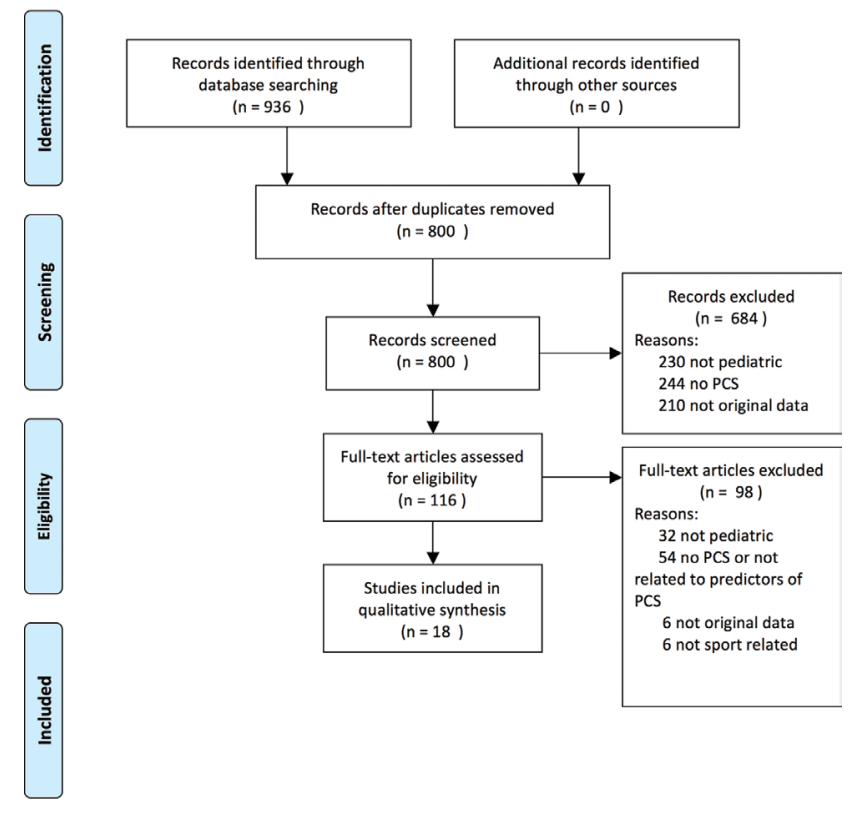

Figure 5 PRISMA flow diagram for search results for subquestion (5) What are the predictors of prolonged recovery of concussion in children?

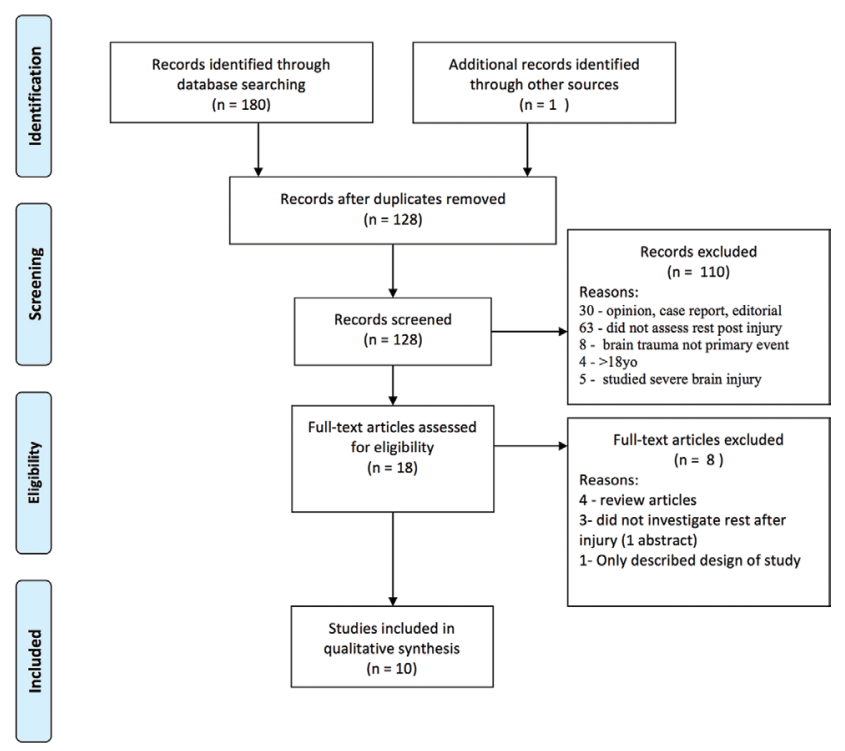

Figure 6 PRISMA flow diagram for search results for subquestion (6) How long should children with sport-related concussion (SRC) rest?

beyond 4 weeks of at least three symptoms compared with state of being prior to the injury), defined based on self-ratings, was present in 31\% of the study participants. The authors developed a 12-point risk score model, which had modest discrimination to stratify PPCS risk at 28 days (area under the curve 0.71 ), and was significantly better than physician judgement in predicting PPCS. The nine variables found to predict the risk of developing PPCS in this selected population were: female sex, age 13 years or older, prior physician diagnosis of migraine, prior concussion with symptoms lasting longer than 1 week, headache, sensitivity to noise, fatigue, answering questions slowly and four or more errors on the Balance Error Scoring System tandem stance. ${ }^{44}$

Across all 18 studies, recurring predictor variables of PPCS were acute headache, migraine and dizziness (all when higher than preinjury levels), as well as female sex and history of receiving multiple concussions.

\section{(6) How long should children with SRC rest?}

Ten articles were included that addressed this question (figure 6); the results are summarised in online supplementary table $6 .^{77101-109}$ Several studies had very small samples, and the larger studies were limited by issues with definitions, compliance, selection bias and recall bias. There were no validated data demonstrating the appropriate duration of cognitive or physical rest in children with SRC.

While the results were variable, the single RCT assessing rest post-SRC in 11-22-year-olds (median age 13.7 years) demonstrated no significant difference in neurocognitive or balance outcomes between those receiving prescribed rest and those receiving usual care, ${ }^{107}$ however, those receiving strict rest reported more symptoms and longer symptom duration.

Exercise at mild or self-selected levels does not appear to prolong symptoms and may shorten symptom duration, and may be particularly beneficial for adolescent athletes. ${ }^{103}$ Small amounts of cognitive activity in the acute setting do not appear to substantially prolong symptoms. High levels of cognitive activity may be associated with longer symptom duration, but athletes engaging in minimal, mild and moderate cognitive activity seem to recover at a similar rate.

A recent study, ${ }^{110}$ presented at the Berlin meeting, included a secondary analysis of 2413 children presenting to ED with 


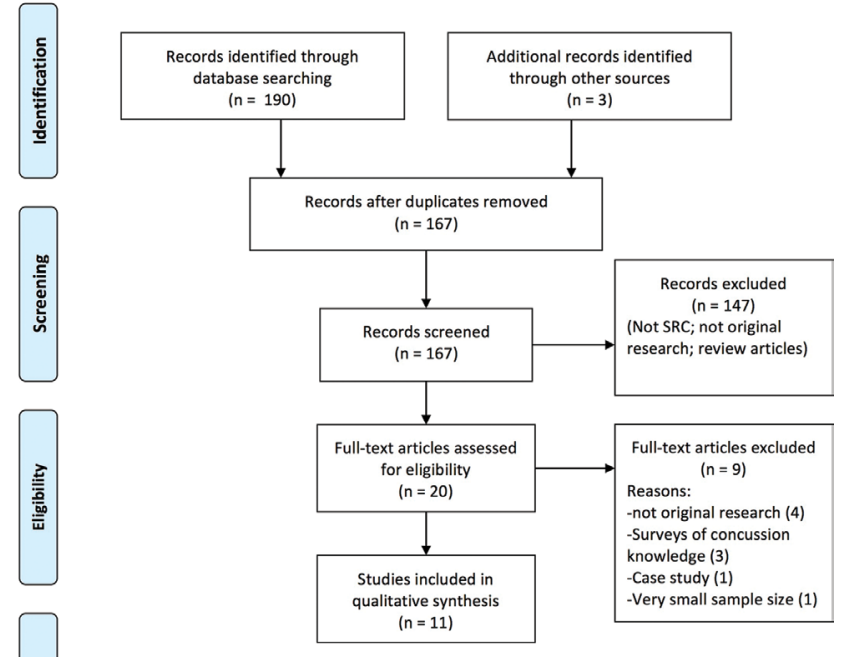

Figure 7 PRISMA flow diagram for search results for subquestion (7) What factors must be considered in 'return to school' following concussion and what strategy or accommodations should be followed? SRC, sport-related concussion.

concussion, which demonstrated that children who participated in physical activity within 7 days of presentation had a reduced rate of PPCS at 28 days compared with those who participated in no physical activity. The study had many limitations, including an observational trial design, with self-reported questionnaires and inability to control for other factors such as cognitive load, and the authors stated that a well designed RCT is required to determine the role of early physical activity following SRC.

\section{(7) What factors must be considered in 'return to school' following concussion and what strategy or accommodations should be followed?}

Eleven articles were included that addressed this question (figure 7); the results are summarised in online supplementary table $7 .{ }^{19} 36507785111-116$

Five factors were found to influence return to school following a concussion:

1. Age: Adolescents tend to have a greater number of and more severe postconcussion symptoms than younger children; tend to take longer to recover and return to school and sport than younger children; and tend to be more concerned about the academic effects of concussion than younger children. ${ }^{36}$ 5085112

2. Symptom load/severity: Students with a greater number of symptoms and more severe symptoms tend to take longer to return to school and require more academic accommodations, as well as taking longer to recover and to RTSp. ${ }^{193685111113114}$

3. School resources: Schools with concussion policies that include student and parent education about concussion tend to practise best-practice guidelines for concussion management; tend to provide more accommodations and greater variety of accommodations to students following concussions; are more likely to form concussion management teams at school to facilitate return to school for concussed students; and have students and parents who are more knowledgeable about concussion. ${ }^{115}$

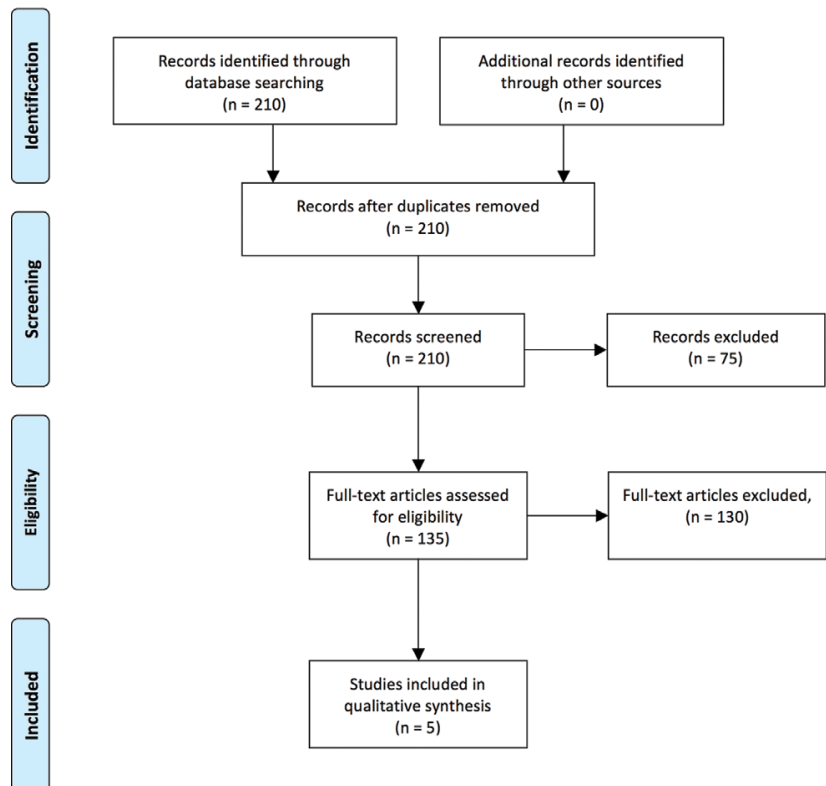

Figure 8 PRISMA flow diagram for search results for subquestion (8) When should children with concussion return to sport?

4. Medical follow-up after injury: Students who receive medical follow-up after an initial assessment in an ED are more likely to receive academic accommodations on return to school following a concussion. ${ }^{116}$

5. Certain subjects: Math poses greater problems for students returning to school after a concussion, followed by reading/ language, arts, science and social studies. ${ }^{36}$

Between $35 \%$ and $73 \%$ of students required academic accommodations and/or experience school difficulty after concussion. ${ }^{1985111114116}$ The literature did not assess specific academic accommodations other than temporary school absence. Postconcussion symptoms such as memory complaints, headache, visual disturbances and vestibular abnormalities may require students to miss some days of school initially after a concussion. ${ }^{19} 365085111113114116$ Most students require only a few days off school (2-5 days), ${ }^{85} 116$ although some evidence suggests that a significant number of students (45\%) may return prematurely, resulting in exacerbation or recurrence of postconcussion symptoms. ${ }^{112}$ Academic accommodations were more likely to be offered to students postconcussion in schools with concussion policies, although mostly informal, and for students who received outpatient medical follow-up after initial assessment in an ED. ${ }^{115} 116$

\section{(8) When should children with concussion RTSp?}

Five articles were included that addressed this question (figure 8); the results are summarised in online supplementary table 8.268589112117 The studies were typically observational cohorts with either prospective or retrospective data acquisition.

A retrospective cohort ${ }^{112}$ of 159 clinic patients showed that elementary school athletes returned to play faster (11.6 days) than high school (25.1 days) or collegiate athletes (23.6 days; $\mathrm{p}<0.02)$. This study documented symptom exacerbation in over $43 \%$ of the entire cohort after return to learn or RTSp. Another retrospective cohort comparing children (8-12 years) with adolescents $(13-17 \text { years })^{85}$ demonstrated a trend for more symptoms and greater symptom severity in adolescents. Younger children became symptom-free significantly faster 
than adolescents ( 12 days vs 14 days, $p=0.04)$, had a lower likelihood of persistent ( $>30$ days) symptoms $(11.3 \%$ vs $30.3 \%$ ) and trended towards a more rapid RTSp (14 days vs 19.5 days, $\mathrm{p}=0.06$ ). Only $14.5 \%$ of children took longer than 1 month to RTSp, compared with $35.3 \%$ of adolescents.

$\mathrm{Kerr}^{26}$ reported on over 1400 concussions from three different cohorts, in which more youth athletes (10\%) RTSp in $<1$ day compared with high school $(1 \%)$ or collegiate athletes $(5 \%)$, and the authors offer several potential reasons for athletes returning to sport prematurely, such as failure to report symptoms and delayed onset of symptoms. Fewer collegiate athletes (7\%) had prolonged RTSp ( $>1$ month) than youth $(16 \%)$ or high school athletes $(20 \%)$. McKeon ${ }^{117}$ found that 35\% of high school students with concussion RTSp in 3-6 days, $71 \%$ in $7-9$ days and $89 \%$ by 21 days. No comparison was made to adults or younger children. Another study of high school and collegiate athletes found that symptoms, visual memory and speed composite scores were worse than baseline on postinjury day (PID) 2 and 7, with resolution by PID 14 . Verbal memory composite scores continued to show deficits at PID 14. This study emphasises the need for multimodality clinical assessment but did not distinguish recovery curves for high school and collegiate athletes. ${ }^{89}$

\section{DISCUSSION}

The purpose of this systematic review was to identify important differences between children and adults in SRC management. We have deliberately restricted the review to SRC, rather than include more general studies of mild traumatic brain injury, because the latter often include a broader range of mechanisms and injuries. The questions we studied were developed to conform to the requirements for the 5th International Consensus Conference on Concussion in Sport in Berlin 2016.

\section{AGE}

In recognition that the age range of this review covers a time of extensive brain maturation and crosses over several functional developmental stages, we paid attention to how age was treated across studies. Identification of how concussion varies across the younger age span, may enable the establishment of different age classifications that will guide clinicians in managing SRC in children and adolescents, and will impact educational, advocacy and legislative public health efforts.

Given the variability of physical, emotional, behavioural and cognitive maturation, at what age do adult management criteria become suitable for children? We did not identify data that provide a clear guide. The most common approach in included studies was to treat the age of 12 years as a cut-off, however, this choice is one of convenience, based on popular usage, given the absence of valid data demonstrating significant differences in terms of diagnostic criteria or therapeutic outcomes. Furthermore, some evidence suggests that children below the age of 8 years require different management paradigms from children 9-12 years, indicating that management of SRC in children may require three groups: $5-8$ years, $9-12$ years and over 12 years. Other research indicates that school level may be a more appropriate age discriminator. While the school levels in the USA include middle school, this is not a classification used in many other countries, and is best avoided in studies on SRC. Currently, there are no defined, evidence-based age groups for the management of youth SRC. However, some research support exists for the following recommendations.

\section{RECOMMENDATIONS}

1. Child-specific paradigms for SRC management should apply to children ages 5-12 years and adolescent-specific paradigms should apply to those ages $13-18$ years.

2. Further research is required to determine the roles of age and development on SRC management paradigms.

\section{SYMPTOMS AND SIGNS}

It is unclear which symptoms and signs are most sensitive and specific in SRC in children. This is partly due to the propensity for studies to select participants from concussion clinics or EDs, which represent only a small proportion of SRC. Furthermore, in the absence of a suitable concussion biomarker, defining the presence or absence of concussion is dependent on the same symptom and sign variables that require validation. It is not known whether different symptoms and signs are age-specific.

Some signs clearly demonstrate concussion (eg, loss of consciousness, impact seizure), but given their absence in the majority of concussions, we need more research to determine which symptoms and signs are highly sensitive and specific to concussion in children, and what level of symptoms (number, severity, change from preinjury function) is reflective of recovery. What is the appropriate method to validate the symptoms and signs, and in particular, to distinguish between concussion and other sequelae of head trauma, such as migraine, neck injury and depression? At the very least, studies are needed that examine the sensitivity and specificity of signs and symptoms by comparing children with concussion to children with these and other disorders, as opposed to 'healthy' children or those with orthopaedic injuries.

The utility of a validated list of symptoms and signs applies to the diagnosis of SRC, and to tracking recovery and predicting prolonged recovery.

\section{RECOMMENDATIONS}

1. An age-appropriate, validated symptom rating scale should be used as a component of the diagnostic evaluation in children presenting with suspected SRC.

2. An age-appropriate, validated symptom rating scale should be used to assess recovery in children with SRC.

3. Further research is needed to determine whether certain symptoms or signs have greater diagnostic or prognostic accuracy than others, and whether their accuracy varies as a function of children's age.

\section{COMPUTERISED NEUROPSYCHOLOGICAL TESTS}

The widespread use of CNT (eg, immediate post-concussion assessment and cognitive test (ImPACT), CogSport) has been adopted in some countries as a mainstay of concussion management in children. While limited data support the use of these tests in select, male, high school athletes, there are no data to support the use of such tests in younger children with SRC. In most cases of child and adolescent SRC, symptom checklists and clinical assessment are sufficient to diagnose concussion.

Any CNT must include measures that are sensitive to change. The reliability of CNT in children is limited by the significant variability of change over time due to age-related cognitive development, such that children's baselines are constantly changing. In attempts to mitigate against the unreliability of preinjury baseline data, reference to population norms is often used. ${ }^{43} 89118119$ However, children who suffer SRC may not be representative of the general population, with a greater proportion being male, and a significant proportion with $\mathrm{ADHD}^{120}$ and/or learning 
disorders. Thus, using population norms (rather than individual preinjury scores) to identify what is abnormal is also problematic, and probably overestimates deficits, particularly those in the attention, memory and learning domains, which are often lower than normal in children with ADHD, learning disorders, and so on.

The results of CNT can be significantly affected by many factors, including the testing venue (background lighting, noise, distractions, group versus individual administration), athlete fatigue (sleep disturbance, time of day), practice effect, feigned poor performance at baseline testing, age, and so on. ${ }^{121} 122$

CNTs offer several potential advantages relative to standard neuropsychological tests, including a more precise assessment of processing speed and reaction time, better standardised assessment, and automated randomisation. Nonetheless, several key questions need to be addressed before it is possible to accurately diagnose and assess recovery in paediatric SRC using CNTs (eg, sensitivity and specificity of CNTs versus standard neuropsychological tests in SRC). Further, additional independent studies are necessary to verify the psychometric properties of the most common CNTs, particularly in paediatric populations.

There remains debate about the clinical role of CNT, specifically regarding the timing of testing (ie, symptomatic vs asymptomatic). While some practitioners advocate testing only once the athlete is asymptomatic, others use CNT in the acute symptomatic stages, to monitor recovery, and some practitioners use CNT in those athletes with delayed recovery, who, by definition, remain symptomatic.

CNT is merely a tool at the disposal of the clinician, and as a stand-alone test does not constitute concussion assessment. While CNT has a role in select cases when used by a qualified practitioner, it does not replace the expertise and experience of the clinician in the assessment and management of SRC in children, and has no validated role in prevention strategies. The issues with stability of testing over time significantly limit the use of CNT in childhood SRC.

\section{RECOMMENDATIONS}

1. At this time, the widespread routine use of baseline CNT is not recommended in children and adolescents, given problems with reliability over time and insufficient evidence of diagnostic or prognostic value.

2. CNT may be used under appropriate qualified supervision as an adjunct to clinical assessment in adolescents with SRC.

3. When using CNT in children and adolescents with SRC, reference to normative data should be done cautiously.

4. In children and adolescents with SRC, CNT should not be used in isolation in concussion management, but, if used, should be combined with a multimodal clinical assessment.

5. Further research is required to assess the utility of $\mathrm{CNT}$ in SRC in children and adolescents, in assessing diagnosis and recovery from concussion.

\section{NORMAL DURATION OF RECOVERY}

This review supports the common assertion that children take longer to recover than adults following SRC. While many children recover in less than 2 weeks, many remain symptomatic up to 1 month and even beyond. Some evidence suggests age differences in recovery, with 13-14-year-olds possibly taking longer to recover than other age groups. ${ }^{19}$ However, in many hospital-based or clinic-based studies, children with prolonged concussion symptoms are more likely to be referred, thus introducing a clinical ascertainment bias.

The definition of recovery has not been clearly established. Some of the definitions used include (1) the use of clinical assessment alone, (2) the use of symptom checklists, (3) The International Classification of Diseases criteria, (4) resolution of all symptoms, (5) return to baseline symptom level and (6) fewer than three symptoms. Future studies should establish an appropriate definition for SRC recovery in children.

\section{RECOMMENDATIONS}

1. Expected duration of symptoms in children with SRC should be defined as up to 4 weeks.

2. Prolonged duration of symptoms in children with SRC should be defined as greater than 4 weeks.

3. Further research is required to establish a working definition of SRC recovery in children and adolescents.

4. Further research is required to determine the normal duration of recovery following SRC in children and adolescents at the community level.

\section{PROLONGED RECOVERY}

Identifying children likely to have prolonged recovery after SRC is an important component of concussion assessment because it may influence the management of the patient's symptoms, help allay parental anxiety, and assist with return to school and return to play recommendations. Given the variable time point for assessment of prolonged recovery in the retrieved studies ( 2 weeks, 1 month and 3 months), it is not surprising that the incidence of prolonged recovery varied from $11 \%$ to $55 \%$. Because children with prolonged symptoms are more likely to present to hospitals and concussion clinics, studies selecting participants from these locations are likely to demonstrate a higher incidence of prolonged recovery. The most consistent predictors of prolonged recovery were headache, history of migraine, female sex, dizziness and a history of receiving multiple concussions. However, data are insufficient regarding predictors of prolonged recovery in children at the community level with SRC who do not present to EDs or specialty clinics, and who may be considered to have had 'milder' concussions.

A distinction between persistent/prolonged symptoms and secondary reaction to concussion in children has not been clearly defined; however, clinical experience suggests that a subgroup of children and adolescents with SRC develop a significant secondary reaction to SRC, including headache, depression and anxiety. A secondary reaction may be due to a combination of factors, including the desire to play sport while recovering, a sense of 'letting the team down', concerns about missing team selections or finals, worries about falling behind with school work, concerns about peer group perceptions of the injured child, and parental anxiety and concerns. Whether a biological basis, such as delayed neurometabolic cascade, may also contribute is unknown. Differentiating between the primary symptoms of SRC and secondary reaction to SRC in children and adolescents requires further evaluation.

\section{RECOMMENDATIONS}

1. The determination of prognosis for prolonged symptoms should take multiple risk factors into account, including variables of headache, migraine history, female sex, dizziness and a history of receiving multiple head injuries. 
2. Further research is required to identify predictors of prolonged recovery of SRC in children and adolescents at the community level.

3. Further research is required to differentiate secondary reaction to SRC from primary prolonged symptoms.

\section{REST}

Previous CISG statements have identified rest, both cognitive and physical, as 'the cornerstone of management of concussion', until an athlete is asymptomatic. However, the evidence for this recommendation is not strong, and in particular, the optimal duration of rest in children has not been clearly articulated. We found that, while rest in the first few days following SRC in children may be beneficial, prolonged rest has not demonstrated any advantage and may even delay recovery. This applies to both physical and cognitive rest.

The intensity of physical and cognitive activity does seem to correlate with recovery. Mild to moderate levels of both cognitive and physical activity are correlated with improved outcomes compared with high-intensity levels of activity. These effects may be age-dependent, ${ }^{103}$ with some evidence suggesting greater response to mild-to-moderate exercise in adolescents compared with other age groups. ${ }^{103}$

\section{RECOMMENDATIONS}

1. Similar to adults, a brief period of cognitive and physical rest is advised following SRC in children. Symptom-limited physical and cognitive activity should then be gradually introduced.

2. Prolonged rest may prolong symptoms following SRC in children, and is therefore not recommended.

3. Further research is required to determine the ideal duration and type of physical and cognitive rest in children following SRC.

\section{RETURN TO SCHOOL}

Children face different issues than adults following SRC, with return to school/learning being a key goal in the management paradigm. For children and adolescents with rapid recovery from SRC, returning to school may be straightforward and require a minimum of support. However, students with more symptoms or severe symptoms may have greater difficulty with return to school. Adolescents tend to have more symptoms, greater severity of symptoms, greater academic demands and are more concerned about the academic impact of concussions than younger children, and may have more difficulty getting back to school.

Initially, students may require a temporary absence from school, usually no more than a few days. However, the optimal length of school absence is unknown, and is likely to vary depending on persistence of symptoms. Most guidelines for return to school recommend minimising the length of time away from school and state that students do not need to be symptom-free to resume school, although there are no validated data available to support this assertion. ${ }^{123} 124$

Upon return to school, approximately $35 \%-73 \%$ of children may require academic accommodations to avoid exacerbation of symptoms. The research examined for this review did not specify the types of academic accommodations, but many review articles outline symptom-specific accommodations that can be instituted, such as reduced school attendance, frequent breaks, more time for tests and assignments, preferential seating in the classroom and shorter assignments. ${ }^{125-128}$ Academic accommodations are more likely to be offered to children who have regular medical follow-up in the first month after injury, and in schools with a concussion policy.

\section{RECOMMENDATIONS}

1. All schools are encouraged to have a concussion policy that includes education on SRC prevention and management for teachers, staff, students and parents, and should offer appropriate academic accommodations and support to students recovering from SRC.

2. Students should have regular medical follow-up following an SRC to monitor recovery and help with return to school.

3. Students may require temporary absence from school after injury.

4. Clinicians should assess risk factors/modifiers that may prolong recovery and require more/prolonged/formal academic accommodations. In particular, adolescents may require more academic support during concussion recovery.

5. Further research is required to determine the appropriate return to school accommodations for children and adolescents with prolonged SRC symptoms.

\section{RETURN TO SPORT}

Current recommendations for RTSp for children have been extrapolated from the adult RTSp consensus guidelines. Adult guidelines have been based on resolution of markers of impaired neurological function (symptoms, cognitive dysfunction, impaired balance) at rest and with gradually increasing exertion. This is primarily to avoid increased risk for repeat injury and potentially worse outcome after repeat injury in those returning prior to full recovery. The relationship between RTSp and return to school is another critical element in management of SRC in children.

Return to contact risk prior to full recovery may predispose to repeat injury and therefore is not recommended. Cognitive or non-contact physical activity might increase symptoms, but it is likely that cognitive activity and gentle, non-contact, aerobic exercise would not predispose to worsened or repeat brain injury. In addition, prolonged inactivity is known to result in greater symptom reporting and delayed recovery. ${ }^{107}$

No consistent evidence is available to indicate optimal timing for children or adolescents to RTSp compared with adults. In general, age appears to be an important variable, and studies not limited to SRC show symptom resolution among high school athletes taking longer than collegiate athletes. ${ }^{129}$ These have led to more conservative recommendations for RTSp in youth athletes, but specific criteria are lacking. When limited to SRC studies, RTSp in childhood age groups have demonstrated that adolescents had more symptoms, longer RTSp and higher proportions of slow-to-recover individuals than younger school children.

Children requiring regular medication use to control symptoms require expert clinical assessment before RTSp decisions can be made.

\section{RECOMMENDATIONS}

1. Children and adolescents should not RTSp until they have successfully returned to school, however early introduction of symptom-limited physical activity is appropriate.

2. Children and adolescents with SRC should commence a modified non-contact exercise programme, supervised by qualified personnel, before full contact training and/or game day play can resume.

3. Further research is required on the criteria for RTSp following SRC in children and adolescents.

4. Further research is required on the timing for RTSp following SRC in children and adolescents. 


\section{LIMITATIONS}

Few studies specific to childhood SRC could be identified. Of those, most involved high school and collegiate students, rather than younger children. This is particularly problematic in the 5-12 years age group.

Most studies in child sports concussion are from North America, and it is unknown whether there are geographical differences that are inadequately accounted for. Some of these geographical differences may include sport-specific differences, such as American football versus Australian football versus rugby. Further, we excluded non-English language studies, which may introduce further cultural and geographical biases.

Other limitations include cross-sectional and retrospective designs with few RCTs; inconsistent definitions of concussion and prolonged recovery; no biomarker is yet available for concussion diagnosis and recovery; reliable, objective measures for cognitive assessment in the sideline setting are unavailable; and long-term outcome data in SRC in children are lacking.

Preinjury learning and behaviour difficulties can predispose children to SRC (by virtue of sports played and style of play) and impact significantly on the clinical presentation of SRC in children. Many of the reviewed studies excluded such children, yet these children form a significant proportion of patients in concussion clinics. Therefore, future studies should address this population of children with SRC.

We assessed the risk of bias in a subset of included articles because, for some study designs, all studies suffer from the same biases, and the tools to assess bias risk do not adequately apply to the relevant studies. Most studies of SRC in children suffer from significant clinical ascertainment bias, particularly those performed in hospital EDs and concussion clinics. In some studies, SRC is grouped with other mechanisms of injury, including motor vehicle accidents, assaults and falls, while others failed to distinguish between severity of injury.

Given these limitations, our recommendations cannot be considered level 1 evidence. All of our recommendations are based on this systematic review, and when required, our expert consensus as an author group, and the expert consensus of the CISG.

\section{CONCLUSIONS}

The management of SRC in children requires special paradigms suitable for the developing child. The paucity of studies that are specific to children, especially younger children, needs to be addressed as a priority, with the expectation that future CISG consensus meetings will have sufficient studies to review that are age-specific, of high quality and with a low risk of bias. Until such time, this review documents the best available evidence for the management of SRC in children and adolescents.

\section{What is already known?}

- The effects of sport-related concussion (SRC) in children are different from adults.

- Children may take longer to recover from SRC than adults.

- Return to school is a priority in the management of children following SRC.
What are the new findings?

- Children and adolescents are expected to take up to 4 weeks to recover following SRC.

- The widespread routine use of baseline computerised neuropsychological testing is not recommended in children and adolescents.

- A brief period of cognitive and physical rest following SRC in children and adolescents should be followed with gradual symptom-limited physical and cognitive activity.

- All schools be encouraged to have a concussion prevention and management policy and should offer appropriate academic accommodations and support to students recovering from SRC.

Correction notice This paper has been amended since it was published Online First. Owing to a scripting error, some of the publisher names in the references were replaced with 'BMJ Publishing Group'. This only affected the full text version, not the PDF. We have since corrected these errors and the correct publishers have been inserted into the references.

Acknowledgements The authors thank Helen Baxter, Austin Health Library, for peer review of search strategy, Arfa Saeed for conducting the literature search and reviewing studies for question (2), Vanessa Rausa for co-conducting the literature search and review of studies for question (3), Liza Bialy and Andre-Anne Ledoux for their assistance with the literature search and review of studies for question (5) and Margaret Sampson for assistance with drafting the search strategy.

Competing interests GAD is an honorary member of the Australian Football League Concussion Working Group and has attended meetings organised by sporting organisations including the NFL (USA), National Rugby League (Australia) and FIFA(Switzerland); however, he has not received any payment, research funding or other monies from these groups other than for travel costs. GAG receives royalties as a test author from Psychological Assessment Resources, receives research funding from the CDC and NIH, receives speaking Honoria for professional lectures, and is on the pediatric mild traumatic brain injury guidelines panel of the CDC. CCG receives grants/research support from NIH, NCAA, DoD, Today's and Tomorrow's Children Fund, UCLA Brain Injury Research Center, UCLA Faculty Grants Program, UCLA Steve Tisch Brain SPORT program, Avanir (research grant 2016-2017), NINDS Neural Analytics SBIR grant (2016-2018) Consultant:NFL-Neurological Care Program, NHLPA, Neural Analytics Inc (2015-16), is on the advisory panel of Love Your Brain, MLS, NBA, NCAA, USSF, performs medicolegal work 1-2 cases annually, and speaks on the Medical Education Speakers Network. WM has received research grants from National Hockey League Alumni Association \& NFL Players Association, receives publishing royalties from Wolters Kluwer, Springer International \& ABC-Clio publishing. RSM receives consultancy fees from Leigh Valley Hospital, is the owner/ director of Sports Concussion Center of New Jersey, speakers fees from National Academy of Neuropsychology; Nemours Dupont Children's Hospital; Notre Dame High School, Lawrenceville, NJ., Pearson International, publishing royalties from Dartmouth College Press, \& Psychology Press, and travel expenses from Moms TEAM Institute. LP is an expert consultant to mdBriefcase in the development of an online concussion education module and has received speaking honoraria/ travel expenses for presentations at scientific meetings. PS serves as a scientific consultant to ImPACT Applications, Inc., and is a member of their scientific advisory board. KJS has received speaking honoraria for presentations at scientific meetings. She is a physiotherapy consultant at Evidence Sport and Spinal Therapy in Calgary, Alberta, Canada, and for athletic teams. MT has received research grant from Royal Children's Hospital Foundation. KOY has received grant funding from NIH and Canadian Institutes of Health Research and book royalties from Guilford Press and Cambridge University Press and has occasionally served as an expert witness in forensic cases; he is President-Elect of the International Neuropsychological Society and a member of the Expert Panel on Acute Diagnosis and Management of Mild Traumatic Brain Injury among Children and Adolescents convened by the Centers for Disease Control and Prevention. RZ holds active grants in pediatric concussion from CIHR, Ontario Neurotrauma Foundation, and the Ontario SPOR Support Unit; and his work is partially supported by the University of Ottawa Brain and Mind Research Institute through a clinical research chair in pediatric concussion. VA, FEB have nothing to declare.

Provenance and peer review Commissioned; externally peer reviewed.

(c) Article author(s) (or their employer(s) unless otherwise stated in the text of the article) 2017. All rights reserved. No commercial use is permitted unless otherwise expressly granted. 


\section{REFERENCES}

1 PedenMMU. World Health Organization. World report on child injury prevention. Geneva, Switzerland New York, NY: UNICEF, 2008.

2 Crowe L, Babl F, Anderson V, et al. The epidemiology of paediatric head injuries: data from a referral centre in Victoria, Australia. J Paediatr Child Health 2009;45:346-50.

3 Lyttle MD, Crowe L, Oakley E, et al. Comparing CATCH, CHALICE and PECARN clinical decision rules for paediatric head injuries. Emerg Med J 2012;29:785-94.

4 Arbogast KB, Curry AE, Pfeiffer MR, et al. Point of health care entry for youth with concussion within a large pediatric care network. JAMA Pediatr 2016;170:e160294.

5 Aubry M, Cantu R, Dvorak J, et al; Concussion in Sport Group. Summary and agreement statement of the first international conference on concussion in sport, Vienna 2001. recommendations for the improvement of safety and health of Athletes who may suffer concussive injuries. Br J Sports Med 2002;36:6-10.

$6 \mathrm{McC}$ rory P, Johnston K, Meeuwisse W, et al. Summary and agreement statement of the 2nd international conference on concussion in sport, Prague 2004. Clinical Journal of Sport Medicine 2005;15:48-55.

7 McCrory P, Meeuwisse W, Johnston K, et al. Consensus statement on concussion in sport: the 3rd international conference on concussion in sport held in Zurich, November 2008. Br J Sports Med 2009;43 Suppl 1(Suppl 1):i76-i84.

8 McCrory P, Meeuwisse WH, Aubry M, et al. Consensus statement on concussion in sport: the 4th international conference on concussion in sport held in Zurich, November 2012. Br J Sports Med 2013;47:250-8.

9 Wells GA, Shea B, O'Connell D, et al The Newcastle-Ottawa scale (NOS) for assessing the quality of nonrandomised studies in meta-analyses

10 OCEBM Levels of Evidence Working Group. "The Oxford Levels of Evidence 2". 2011.

11 Anderson V, Catroppa C, Morse S, et al. Recovery of intellectual ability following traumatic brain injury in childhood: impact of injury severity and age at injury. Pediatr Neurosurg 2000;32:282-90.

12 Anderson VA, Morse SA, Klug G, et al. Predicting recovery from head injury in young children: a prospective analysis. J Int Neuropsychol Soc 1997;3:568-80.

13 Babcock L, Byczkowski T, Wade SL, et al. Predicting postconcussion syndrome after mild traumatic brain injury in children and adolescents who present to the emergency department. JAMA Pediatr 2013;167:156-61.

14 Baillargeon A, Lassonde M, Leclerc S, et al. Neuropsychological and neurophysiological assessment of sport concussion in children, adolescents and adults. Brain Inj 2012;26:211-20.

15 Bakhos LL, Lockhart GR, Myers R, et al. Emergency department visits for concussion in young child Athletes. Pediatrics 2010;126:e550-e556.

16 Barlow KM, Crawford S, Stevenson A, et al. Epidemiology of postconcussion syndrome in pediatric mild traumatic brain injury. Pediatrics 2010;126:e374-e381.

17 Blume HK, Vavilala MS, Jaffe KM, et al. Headache after pediatric traumatic brain injury: a cohort study. Pediatrics 2012;129:e31-e39.

18 Browne GJ, Lam LT. Concussive head injury in children and adolescents related to sports and other leisure physical activities. Br J Sports Med 2006;40:163-8.

19 Corwin DJ, Zonfrillo MR, Master CL, et al. Characteristics of prolonged concussion recovery in a pediatric subspecialty referral population. J Pediatr 2014;165:1207-15.

20 Covassin T, Elbin RJ, Harris W, et al. The role of age and sex in symptoms, neurocognitive performance, and postural stability in Athletes after concussion. Am J Sports Med 2012;40:1303-12.

21 Eisenberg MA, Andrea J, Meehan W, et al. Time interval between concussions and symptom duration. Pediatrics 2013;132:8-17.

22 Field M, Collins MW, Lovell MR, et al. Does age play a role in recovery from sportsrelated concussion? A comparison of high school and collegiate Athletes. J Pediatr 2003; 142:546-53.

23 Grubenhoff JA, Kirkwood M, Gao D, et al. Evaluation of the standardized assessment of concussion in a pediatric emergency department. Pediatrics 2010;126:688-95.

24 Hunt TN, Ferrara MS. Age-Related differences in neuropsychological testing among high school Athletes. J Athl Train 2009;44:405-9.

25 Jinguji TM, Bompadre V, Harmon KG, et al. Sport concussion assessment tool - 2: Baseline Values for High School Athletes. Br J Sports Med 2012;46:365-70.

26 Kerr ZY, Zuckerman SL, Wasserman EB, et al. Concussion symptoms and return to play time in youth, high school, and college american football Athletes. JAMA Pediatr 2016;170:647-53.

27 Kontos AP, Elbin RJ, Fazio-Sumrock VC, et al. Incidence of Sports-Related concussion among youth football players aged 8-12 years. J Pediatr 2013;163:717-20

28 Lichtenstein JD, Moser RS, Schatz P. Age and test setting affect the prevalence of invalid baseline scores on neurocognitive tests. Am J Sports Med 2014;42:479-84.

29 McKay CD, Brooks BL, Mrazik M, et al. Psychometric properties and reference values for the ImPACT neurocognitive test battery in a sample of elite youth ice hockey players. Archives of Clinical Neuropsychology 2014;29:141-51.

30 Meehan WP. 3rd, Mannix R, Monuteaux MC, et al. early symptom burden predicts recovery after sport-related concussion. Neurology 2014;83:2204-10.

31 Meehan WP, Mannix RC, Stracciolini A, et al. Symptom severity predicts prolonged recovery after Sport-Related concussion, but age and amnesia do not. J Pediatr 2013;163:721-5
32 Moser RS, Schatz P, Grosner E, et al. One year Test-retest reliability of neurocognitive baseline scores in 10- to 12-year olds. App/ Neuropsycho/ 2016:1-6.

33 National electronic injury surveillance system (NEISS). NEISS data highlights: estimated number of injuries and estimated rate of Product-related injuries treated in hospital emergency departments. CPSC National Information Clearinghouse 2007.

34 Olson B. Balance error scoring system normative values in an athletic pediatric sample. Athletic Training \& Sports Health Care 2012;4:141.

35 Quatman-Yates C, Hugentobler J, Ammon R, et al. The utility of the balance error scoring system for mild brain injury assessments in children and adolescents. Phys Sportsmed 2014;42:32-8.

36 Ransom DM, Vaughan CG, Pratson L, et al. Academic effects of concussion in children and adolescents. Pediatrics 2015;135:1043-50.

37 Register-Mihalik JK, Kontos DL, Guskiewicz KM, et al. Age-related differences and reliability on computerized and paper-and-pencil neurocognitive assessment batteries. J Ath/ Train 2012:47:297-305.

38 Reynolds E, Fazio VC, Sandel N, et al. Cognitive development and the immediate postconcussion assessment and cognitive testing: a case for separate norms in preadolescents. App/ Neuropsychol 2016;5:283-93.

39 Sady MD, Vaughan CG, Gioia GA. Psychometric characteristics of the postconcussion symptom inventory in children and adolescents. Archives of Clinical Neuropsychology 2014;29:348-63.

40 Schneider KJ, Emery CA, Kang J, et al. Examining sport concussion assessment tool ratings for male and female youth hockey players with and without a history of concussion. Br J Sports Med 2010:44:1112-7.

41 Tonks J, Huw Williams W, Yates P, et al. Cognitive correlates of psychosocial outcome following traumatic brain injury in early childhood: comparisons between groups of children aged under and over 10 years of age. Clin Child Psychol Psychiatry 2011;16:185-94.

42 Valovich McLeod TC, Bay RC, Lam KC, et al. Representative baseline values on the sport concussion assessment tool 2 (SCAT2) in adolescent Athletes vary by gender, grade, and concussion history. Am J Sports Med 2012;40:927-33.

43 Williams J, Crowe LM, Dooley J, et al. Developmental trajectory of InformationProcessing skills in children: computer-based assessment. App/ Neuropsychol 2016:5:35-43.

44 Zemek R, Barrowman N, Freedman SB, et al; for the Pediatric Emergency Research Canada (PERC) Concussion Team. Clinical risk score for persistent postconcussion symptoms among children with acute concussion in the ED. Jama 2016;315:1014-25.

45 Lee YM, Odom MJ, Zuckerman SL, et al. Does age affect symptom recovery after sports-related concussion? A study of high school and college Athletes. J Neurosurg 2013;12:537-44.

46 Majerske CW, Mihalik JP, Ren D, et al. Concussion in sports: postconcussive activity levels, symptoms, and neurocognitive performance. J Athl Train 2008;43:265-74.

47 Snyder AR, Bauer RM; Health IMPACTS for Florida Network. A normative study of the sport concussion assessment tool (SCAT2) in children and adolescents. Clin Neuropsychol 2014;28:1091-103.

48 Asplund CA, McKeag DB, Olsen CH. Sport-related concussion: factors associated with prolonged return to play. Clin J Sport Med 2004;14:339-43.

49 Lee MA, Fine B. Adolescent concussions. Conn Med 2010;74:149-56.

50 Lovell MR, Collins MW, Iverson GL, et al. Recovery from mild concussion in high school Athletes. J Neurosurg 2003;98:296-301.

51 Schatz P, Pardini JE, Lovell MR, et al. Sensitivity and specificity of the ImPACT test battery for concussion in Athletes. Arch Clin Neuropsychol 2006;21:91-9.

52 Kontos AP, Covassin T, Elbin RJ, et al. Depression and neurocognitive performance after concussion among male and female high school and collegiate Athletes. Arch Phys Med Rehabil 2012;93:1751-6.

53 Collins MW, Field M, Lovell MR, et al. Relationship between postconcussion headache and neuropsychological test performance in high school Athletes. Am J Sports Med 2003;31:168-73.

54 Covassin T, Elbin RJ, Nakayama Y. Tracking neurocognitive performance following concussion in high school Athletes. Phys Sportsmed 2010;38:87-93.

55 Hang B, Babcock L, Hornung R, et al. Can computerized neuropsychological testing in the emergency department predict recovery for young Athletes with concussions? Pediatr Emerg Care 2015:31:688-93.

56 Iverson GL, Gaetz M, Lovell MR, et al. Relation between subjective fogginess and neuropsychological testing following concussion. Journal of the International Neuropsychological Society 2004;10:904-6.

57 Kostyun RO, Milewski MD, Hafeez I. Sleep disturbance and neurocognitive function during the recovery from a sport-related concussion in adolescents. Am J Sports Med 2015:43:633-40.

58 Lau BC, Collins MW, Lovell MR. Sensitivity and specificity of subacute computerized neurocognitive testing and symptom evaluation in predicting outcomes after sportsrelated concussion. Am J Sports Med 2011;39:1209-16.

59 Lovell MR, Solomon GS. Neurocognitive test performance and symptom reporting in cheerleaders with concussions. J Pediatr 2013;163:1192-5.

60 Maugans TA, Farley C, Altaye M, et al. Pediatric Sports-Related concussion produces cerebral blood flow alterations. Pediatrics 2012;129:28-37. 
61 Mautner K, Sussman WI, Axtman M, et al. Relationship of attention deficit hyperactivity disorder and postconcussion recovery in youth Athletes. Clinical Journal of Sport Medicine 2015;25:355-60.

62 Pellman EJ, Lovell MR, Viano DC, et al. Concussion in professional football: recovery of NFL and high school Athletes assessed by computerized neuropsychological Testing-Part 12. Neurosurgery 2006;58:263-74.

63 Sandel N, Henry LC, French J, et al. Parent perceptions of their adolescent athlete's Concussion: A Preliminary Retrospective Study. App/ Neuropsychol 2015;4:211-6.

64 Sandel NK, Lovell MR, Kegel NE, et al. The relationship of symptoms and neurocognitive performance to perceived recovery from Sports-Related concussion among adolescent Athletes. App/ Neuropsychol 2013;2:64-9.

$65 \operatorname{Sim}$ A, Terryberry-Spohr L, Wilson KR. Prolonged recovery of memory functioning after mild traumatic brain injury in adolescent Athletes. J Neurosurg 2008; 108:511-6

66 Vernau BT, Grady MF, Goodman A, et al. Oculomotor and neurocognitive assessment of youth ice hockey players: baseline associations and observations after concussion. Dev Neuropsychol 2015;40:7-11.

67 Virji-Babul N, Hilderman CG, Makan N, et al. Changes in functional brain networks following sports-related concussion in adolescents. J Neurotrauma 2014:31:1914-9.

68 Zuckerman SL, Lee YM, Odom MJ, et al. Sports-Related concussion in helmeted vs unhelmeted athletes: who fares worse? Int J Sports Med 2015;36:419-25.

69 Zuckerman SL, Solomon GS, Forbes JA, et al. Response to acute concussive injury in soccer players: is gender a modifying factor?. J Neurosurg Pediatr 2012;10:504-10.

70 Lovell MR, et al. Grade 1 or "Ding" Concussions in High School Athletes. American Journal of Sports Medicine 2004;32:47-54.

71 McGrath N, Dinn WM, Collins MW, et al. Post-exertion neurocognitive test failure among student-athletes following concussion. Brain Inj 2013;27:103-13.

72 Tsushima WT, Shirakawa N, Geling O. Neurocognitive functioning and symptom reporting of high school Athletes following a single concussion. App/ Neuropsychol 2013:2:13-16

73 Black AM, Brooks BL, McLeod RS, et al. The value of computerised neurocognitive testing at medical clearance to return to play following A Sport-Related concussion in youth ice hockey players. Br J Sports Med 2016

74 Crowe L, Collie A, Hearps S, et al. Cognitive and physical symptoms of concussive injury in children: a detailed longitudinal recovery study. Br J Sports Med 2016;50:311-6.

75 Bock S, Grim R, Barron TF, et al. Factors associated with delayed recovery in Athletes with concussion treated at a pediatric neurology concussion clinic. Child's Nervous System 2015:31:2111-6.

76 Bramley H, Heverley S, Lewis MM, et al. Demographics and treatment of adolescent posttraumatic headache in a regional concussion clinic. Pediatr Neurol 2015;52:493-8.

77 Brown NJ, Mannix RC, O'Brien MJ, et al. Effect of cognitive activity level on duration of Post-Concussion symptoms. Pediatrics 2014;133:e299-e304.

78 Cantu RC, Guskiewicz K, Register-Mihalik JK. A retrospective clinical analysis of moderate to severe athletic concussions. Pm R 2010;2:1088-93.

79 Eisenberg MA, Meehan WP, Mannix R. Duration and course of Post-Concussive symptoms. Pediatrics 2014;133:999-1006.

80 Henry LC, Elbin RJ, Collins MW, et al. Examining recovery trajectories after SportRelated concussion with a multimodal clinical assessment approach. Neurosurgery 2016;78:232-41

81 Kriz PK, Stein C, Kent J, et al. Physical maturity and concussion symptom duration among adolescent ice hockey players. J Pediatr 2016;171:234-239e1-239.

82 Nelson LD, Guskiewicz KM, Barr WB, et al. Age differences in recovery after SportRelated concussion: a comparison of high school and collegiate Athletes. J Athl Train 2016;51:142-52

83 Nelson LD, Tarima S, LaRoche AA, et al. Preinjury somatization symptoms contribute to clinical recovery after sport-related concussion. Neurology 2016;86:1856-63.

84 O'Kane JW, Spieker A, Levy MR, et al. Concussion among female Middle-School soccer players. JAMA Pediatr 2014;168:258-64.

85 Purcell L, Harvey J, Seabrook JA. Patterns of recovery following Sport-Related concussion in children and adolescents. Clin Pediatr 2016;55:452-8.

86 Seiger A, Goldwater E, Deibert E. Does mechanism of injury play a role in recovery from concussion? Journal of Head Trauma Rehabilitation 2015;30:E52-E56.

87 Terwilliger VK, Pratson L, Vaughan CG, et al. Additional Post-Concussion impact exposure may affect recovery in adolescent Athletes. J Neurotrauma 2016;33:761-5.

88 Zuckerman S, Lee Y, Odom M, et al. Recovery from sports-related concussion: days to return to neurocognitive baseline in adolescents versus young adults. Surg Neurol Int 2012;3:130.

89 McClincy MP, Lovell MR, Pardini J, et al. Recovery from sports concussion in high school and collegiate Athletes. Brain Inj 2006;20:33-9.

90 Barr WB, Prichep LS, Chabot R, et al. Measuring brain electrical activity to track recovery from sport-related concussion. Brain Inj 2012;26:58-66.

91 Grubenhoff JA, Deakyne SJ, Brou L, et al. Acute concussion symptom severity and delayed symptom resolution. Pediatrics 2014;134:54-62.

92 Korinthenberg R, Schreck J, Weser J, et al. Post-traumatic syndrome after minor head injury cannot be predicted by neurological investigations. Brain and Development 2004;26:113-7.
93 Thomas DG, Collins MW, Saladino RA, et al. Identifying neurocognitive deficits in adolescents following concussion. Academic Emergency Medicine 2011;18:246-54.

94 Yeates KO, Taylor HG, Rusin J, et al. Longitudinal trajectories of postconcussive symptoms in children with mild traumatic brain injuries and their relationship to acute clinical status. Pediatrics 2009;123:735-43.

95 Zemek R, Clarkin C, Farion KJ, et al. Parental anxiety at initial acute presentation is not associated with prolonged symptoms following pediatric concussion. Academic Emergency Medicine 2013:20:1041-9.

96 Barlow M, Schlabach D, Peiffer J, et al. Differences in change scores and the predictive validity of three commonly used measures following concussion in the middle school and high school aged population. Int I Sports Phys Ther 2011:6:150-7.

97 Merritt VC, Arnett PA. Premorbid predictors of postconcussion symptoms in collegiate Athletes. J Clin Exp Neuropsychol 2014;36:1098-111.

98 Morgan CD, Zuckerman SL, Lee YM, et al. Predictors of postconcussion syndrome after sports-related concussion in young Athletes: a matched case-control study. J Neurosurg 2015:15:589-98.

99 Ponsford J, Willmott C, Rothwell A, et al. Cognitive and behavioral outcome following mild traumatic head injury in children. Journal of Head Trauma Rehabilitation 1999;14:360-72

100 Yeates KO, Luria J, Bartkowski $\mathrm{H}$, et al. Postconcussive symptoms in children with mild closed head injuries. Journal of Head Trauma Rehabilitation 1999; 14:337-50

101 Brooks BL, Low TA, Daya $H$, et al. Test or rest? computerized cognitive testing in the emergency department after pediatric mild traumatic brain injury does not delay symptom recovery. J Neurotrauma 2016:33:2091-6.

102 Gibson S, Nigrovic LE, O'Brien M, et al. The effect of recommending cognitive rest on recovery from sport-related concussion. Brain Inj 2013;27:839-42.

103 Howell DR, Mannix RC, Quinn B, et al. Physical activity level and symptom duration are not associated after concussion. Am J Sports Med 2016;44:1040-6.

104 Moor HM, Eisenhauer RC, Killian KD, et al. The relationship between adherence behaviors and recovery time in adolescents after a sports-related concussion: an observational study. Int I Sports Phys Ther 2015;10:225-33.

105 Moser RS, Schatz P, Glenn M, et al. Examining prescribed rest as treatment for adolescents who are slow to recover from concussion. Brain Inj 2015;29:58-63.

106 Renjilian C, Basta L, Wiebe D, et al. Physical activity in pediatric concussion: using accelerometers to evaluate how total daily activity or physical exertion relate to symptoms. Clinical J Sport Med 2015;25:211

107 Thomas DG, Apps JN, Hoffmann RG, et al. Benefits of strict rest after acute concussion: a randomized controlled trial. Pediatrics 2015;135:213-23.

108 Winkler R, Taylor NF, Children D. Do children and adolescents with mild traumatic brain injury and persistent symptoms benefit from treatment? A systematic review. J Head Trauma Rehabil 2015:30:324-33.

109 Moser RS, Glatts C, Schatz P. Efficacy of immediate and delayed cognitive and physical rest for treatment of sports-related concussion. J Pediatr 2012;161:922-6.

110 Grool AM, Aglipay M, Momoli F, et al; Pediatric Emergency Research Canada (PERC) Concussion Team. Association between early participation in physical activity following acute concussion and persistent postconcussive symptoms in children and adolescents. Jama 2016;316:2504-14

111 Baker JG, Leddy JJ, Darling SR, et al. Factors associated with problems for adolescents returning to the classroom after Sport-Related concussion. Clin Pediat 2015;54:961-8

112 Carson JD, Lawrence DW, Kraft SA, et al. Premature return to play and return to learn after a sport-related concussion: physician's chart review. Can Fam Physician 2014:60:e310-e12-5.

113 Corwin DJ, Wiebe DJ, Zonfrillo MR, et al. Vestibular deficits following youth concussion. J Pediatr 2015;166:1221-5.

114 Darling SR, Leddy JJ, Baker JG, et al. Evaluation of the Zurich guidelines and exercise testing for return to play in adolescents following concussion. Clin J Sport Med 2014;24:128-33.

115 Glang AE, Koester MC, Chesnutt JC, et al. The effectiveness of a web-based resource in improving postconcussion management in high schools. J Adolesc Health 2015;56:91-7.

116 Grubenhoff JA, Deakyne SJ, Comstock RD, et al. Outpatient follow-up and return to school after emergency department evaluation among children with persistent postconcussion symptoms. Brain Inj 2015;29:1186-91.

117 McKeon JM, Livingston SC, Reed A, et al. Trends in concussion return-to-play timelines among high school Athletes from 2007 through 2009. J Athl Train 2013;48:836-43.

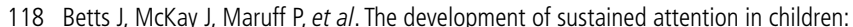
the effect of age and task load. Child Neuropsychol 2006;12:205-21.

119 McKay J, Betts J, Maruff $\mathrm{P}$, et al. An examination of developmental trajectories for attention skills in children. The Australian Educational and Developmental Psychologist 2010;27:76-89

120 Gerschman T, Schneider K, Yeates Y, et al. Attention problems as A risk factor for concussion in youth Ice-Hockey players. British journal of sports medicine 2016.

121 Moser RS, Schatz P, Neidzwski K, et al. Group versus individual administration affects baseline neurocognitive test performance. Am J Sports Med 2011;39:2325-30. 


\section{Review}

122 Vaughan CG, Gerst EH, Sady MD, et al. The relation between testing environment and baseline performance in child and adolescent concussion assessment. Am J Sports Med 2014;42:1716-23.

123 CanChild McMaster University. Return to activity and school guidelines for children and youth.

124 Halstead ME, McAvoy K, Devore CD, et al; Council on Sports Medicine and FitnessCouncil on School Health. Returning to learning following a concussion. Pediatrics 2013:132:948-57.

125 Gioia GA. Multimodal evaluation and management of children with concussion: using our heads and available evidence. Brain Inj 2015;29:195-206.
126 Master CL, Gioia GA, Leddy JJ, et al. Importance of 'return-to-learn' in pediatric and adolescent concussion. Pediatr Ann 2012;41:e160-e166.

127 McGrath N. Supporting the student-athlete's return to the classroom after a sportrelated concussion. J Athl Train 2010:45:492-8.

128 Sady MD, Vaughan CG, Gioia GA. School and the concussed youth: recommendations for concussion education and management. Phys Med Rehabil Clin N Am 2011;22:701-19.

129 Williams RM, Puetz TW, Giza CC, et al. Concussion recovery time among high school and collegiate Athletes: a systematic review and meta-analysis. Sports Med 2015:45:893-903. 